\title{
Rubber curing chemistry governing the orientation of layered silicate
}

\author{
A. Das*, R. Jurk, K. W. Stöckelhuber, G. Heinrich \\ Leibniz-Institut für Polymerforschung Dresden e.V., Hohe Straße 6, D-01069 Dresden, Germany
}

Received 10 July 2007; accepted in revised form 8 September 2007

\begin{abstract}
The effect of curing systems on the orientation and the dispersion of the layered silicates in acrylonitrile butadiene rubber nanocomposite is reported. Significant differences in X-ray diffraction pattern between peroxide curing and sulfur curing was observed. Intense X-ray scattering values in the XRD experiments from peroxide cured vulcanizates indicate an orientation of the layers in a preferred direction as evinced by transmission electron micrographs. However, sulfur cured vulcanizates show no preferential orientation of the silicate particles. Nevertheless, a closer inspection of transmission electron microscopy (TEM) images of peroxide and sulfur cured samples shows exfoliated silicate layers in the acrylonitrile butadiene rubber (NBR) matrix. It was revealed in the prevailing study that the use of an excess amount of stearic acid in the formulation of the sulfur curing package leads to almost exfoliated type X-ray scattering pattern.
\end{abstract}

Keywords: nanocomposites, acrylonitrile butadiene rubber, montmorillonite, orientation, exfoliation

\section{Introduction}

Recently, there has been considerable interest in forming nanocomposites as a means to improve several properties of polymers. For this purpose layered silicates are now widely being used. These layered silicates are a class of inorganic materials that are naturally layered in structure. Layered silicate refers both to natural clays like smectite and to synthetic layered silicates such as magadite and mica. Among natural clays, both montmorillonite and hectorite belong to the smectite family and are the most commonly used layered silicates in nanocomposites due to their high cation exchange capacities, large surface area, good surface reactivity and surface adsorptive properties [1].

A considerable number of elastomer nanocomposites consisting of various rubbers and layered silicates have been reported. Different methods of intercalation of layered silicates, such as melt intercalation [2-6], latex coagulation [7-9] and reactive mixing intercalation [10] method have been adopted to prepare rubber nanocomposites.

Acrylonitrile butadiene rubber (NBR) is commonly considered the workhorse of the several industrial and automotive rubber products. This rubber is manufactured by copolymerization of butadiene and acrylonitrile. By selecting appropriate acrylonitrile content one can tailor the different properties in order to use it in different application areas like roll covers, hydraulic hoses, conveyor belting, graphic arts, oil field packers, seals for all kinds of plumbing and appliance applications and also oil, fuel, and chemical resistance materials. It has also excellent temperature resistance properties with wider short-and long-term operating temperature range as much as $-40^{\circ} \mathrm{C}$ to $+125^{\circ} \mathrm{C}$. Like most unsaturated thermoset elastomers, NBR requires formulating with added ingredients, and further processing to make useful articles. Additional ingredients typically include reinforcement fillers, 
plasticizers, weather protectants, and vulcanization packages.

During the course of rubber curing different types of intermediate chemical species are formed in the rubber matrix. It is expected that vulcanization ingredients can further interact with the organoclay during the vulcanization of rubber at higher temperatures and pressure [11]. These unavoidable interactions could be reflected on the final microstructure of layered silicates.

There is no report stating and comparing the effect of peroxide or sulfur crosslinking on the exfoliation and intercalation process. A group of researchers from Toyota, Japan, reported that ethylene propylene diene monomer (EPDM)-clay nanocomposite can be formed successfully when thiuram sulfide and dithiocarbamate were selected as vulcanization ingredients [4]. They assumed that use of these types of vulcanization accelerators leads to sulfur crosslinking by free radial fashion, which ultimately enhances the gallery gap between two adjacent layers of silicates, and, as a result, the vulcanizates get superior physical properties. On the other hand, use of sulfenamide type accelerator does not bring any positive effect on the exfoliation intercalation process. Recently, Karger-Kocsis et al. reported that primary amine, present as a modifier in the clay, is taking part in the sulfur vulcanization process, and this sulfur vulcanization leads to confined and deintercalated (gallery collapsing) structures of the layered silicate in the hydrogenated nitrile butadiene rubber matrix [12]. In the case of peroxide curing systems they found a passive nature of the primary amine, and finally highly intercalated structures were achieved [13]. However, in their study they have used an organic sulfur compound in peroxide curing formulations which is somewhat surprising. It is expected that zinc oxide along with sulfur containing compound could promote some sort of sulfur crosslinking to the HNBR (hydrogenated acrylonitrile butadiene rubber) matrix though the amount of double bonds is less than $1 \%$. In our present study, quaternary ammonium modified layered silicate has been used as a reinforcing filler in the NBR matrix, and the masterbatch comprised with this filler and NBR was produced by melt mixing method. Attention was given to see the effect of curing chemistry on the intercalation and exfoliation process of the layered silicate. The anisotropic behavior of the filler in the rubber matrix was also investigated by com- paring peroxide and sulfur cured systems. Finally, the excess dose of stearic acid in a sulfur vulcanization formulation was used to investigate the role of this fatty acid on the reinforcement process of layered particles.

\section{Experimental}

Acrylonitrile butadiene rubber (NBR) used in this study was obtained from Lanxess, Leverkusen, Germany (Perbunan 4456 F, Acrylonitrile content [\%] 44.0 \pm 1.5 , Mooney viscosity (ML $(1+4) 100^{\circ} \mathrm{C}$ ) $55 \pm 5$ ). Zinc oxide, stearic acid, and soluble sulfur employed in this study were obtained from Continental AG (Hannover, Germany). Zinc dimethyldithiocarbamate (ZDMC-80) was collected from RheinChemie Rheinau GmbH, Mannheim, Germany. Dicumyl peroxide (synthesis grade) was purchased from Merck, Hohenbrunn Germany. Organomodified montmorillonite (Nanofil 15), was supplied by Süd-Chemie AG, Moosburg, Germany. This clay contains quaternary ammonium salt as organic modifier and the basal spacing of this organoclay is $2.98 \mathrm{~nm}$.

The NBR masterbatch containing $5 \mathrm{phr}$ (parts per hundred of rubber) organoclay was prepared by an internal mixer (Haake PolyLab-System with Banbury type rotor, Thermo Electron GmbH, Karlsruhe, Germany) with $50 \mathrm{rpm}$ rotor speed and $160^{\circ} \mathrm{C}$ initial temperature. This mixing step was done during $10 \mathrm{~min}$. After taking out this masterbatch, it was then cooled in the air and other crosslinking agent/vulcanization ingredients were mixed on a two roll open mixing mill with the friction ratio of $1: 1.2$ rotating at $40^{\circ} \mathrm{C}$ using $10 \mathrm{~min}$ compounding cycle. The curing study was carried out with the help of a moving die rheometer (Scarabaeus V-50, Langgöns, Germany) at $160^{\circ} \mathrm{C}$. The stocks were cured under pressure at $160^{\circ} \mathrm{C}$ to optimum cure $\left(t_{90}\right)$. Philips XRD-6000 wide-angle $\mathrm{X}$-ray instrument (WAXD) with $\mathrm{Cu}-\mathrm{K}_{\alpha}$ radiation (30 kV and $40 \mathrm{~mA}$ ) and a wavelength of $1.542 \AA$ was used for XRD studies. For this experiment round shaped samples were used with diameter of $25 \mathrm{~mm}$ and thickness of about $2 \mathrm{~mm}$. The scanning $2 \theta$ angle ranged between $2^{\circ}$ and $15^{\circ}$ with a step scanning rate of $2 \mathrm{deg} / \mathrm{min}$. Tensile tests have been done with Zwick 1456 (model 1456, Z010, Ulm Germany) with a cross-head speed of $200 \mathrm{~mm} \cdot \mathrm{min}^{-1}$ (ISO 527). For TEM experiments ultra-thin sections were cut by a microtome at about $-100^{\circ} \mathrm{C}$, and 
the images were taken by JEM 2010 with an acceleration voltage of $200 \mathrm{kV}$.

\section{Results and discussion}

\subsection{Effect of vulcanization type}

The combined cure package in a typical rubber compound comprises the cure agent itself (sulfur or peroxide), together with accelerator, antioxidant, activator and retarding agents. Generally, sulfur curing packages are used if more dynamically elastic and flexible properties are desired, like, for example, in tire tread formulations. The peroxide curing system is useful when several other properties are desirable like compression set, abrasion etc. In our present study these two types of curing packages were used in NBR clay composite in order to find the suitability of those on the reinforcement process by layered silicates. The detailed formulations and processing methods are given in Table 1. Mix I is cured with sulfur vulcanization ingredients and Mix II is crosslinked by peroxide. The XRD scans of organoclay and other rubber vulcanizates are shown in Figure 1. The peak corresponding to $d_{001}$ plane of pure organoclay appears at the spacing gap $2.98 \mathrm{~nm}$. The masterbatch containing $5 \mathrm{phr}$ of organoclay shows the peak position at $3.57 \mathrm{~nm}$ which corresponds to the $d_{001}$ plane of the layered silicate. This observation indicates that during mixing at $160^{\circ} \mathrm{C}$ in the internal mixer further increment in the gallery gap is taking place. This means that some sort of intercalation appears by penetration of macromolecular chains into the gallery of the layered silicates. After curing of this masterbatch by a sulfur system the $d_{001}$ plane shows the peak value at $4.35 \mathrm{~nm}$, but also others broad peaks appear for other higher order reflections. This observation reveals the advanced intercalation process of organoclay in the NBR matrix which takes place during sulfur vulcanization. In the pattern of peroxide cured NBR containing $5 \mathrm{phr}$ organoclay, the reflection peak corresponding to a basal spacing $\left(d_{001}\right)$ at $3.69 \mathrm{~nm}$ is relatively more intense compared to the uncured masterbatch compound. Moreover, also the peak intensity is very pronounced as compared with the sulfur cured system. Higher peak intensity means in this case higher orientations in a particular direction of the layered structure [14]. Such type of orientation of the layer silicate in the rubber matrix is expected in the direction of flow during the processing of the rubber compound [2]. The type of crosslinking (sulfur or peroxide) not only influences the degree of intercalation but also significantly affects the order or coherence nature of the layered particles in the amorphous rubber matrix. Though the degree of intercalation of peroxide cured system is less as compared with sulfur system, in peroxide cured system the clay layers are oriented [2]. TEM pictures are giving a direct visual evidence about this orientation and distribution of the layered silicate in the rubber matrix. Figure 2 shows the sulfur vulcanized NBR matrix filled with $5 \mathrm{phr}$ organoclay, mixed at $160^{\circ} \mathrm{C}$ initial temperature and cured at $160^{\circ} \mathrm{C}$. There are lot of small dark lines which indicate the organoclay particles. These silicate particles are finely and uniformly distributed in the whole region of the rubber sample under visual area. The silicate layers in the rubber matrix are oriented randomly in this sulfur cured NBR vulcanized sheet. However, the peroxide cured vulcanizates show that most of the silicates particles are oriented in a particular direction (Figure 3). It is important to note here that both Mix I and Mix II are coming from the same masterbatch, and the same processing procedures were followed to pre-

Table 1. Formulations for the curing of NBR

\begin{tabular}{|c|c|c|c|}
\hline \multirow{3}{*}{$\begin{array}{c}\text { Step I } \\
\text { (Internal mixer) }\end{array}$} & \multicolumn{3}{|c|}{ Material } \\
\hline & NBR & \multicolumn{2}{|c|}{$200 \mathrm{~g}$} \\
\hline & Organoclay & \multicolumn{2}{|c|}{$10 \mathrm{~g}$} \\
\hline \multicolumn{2}{|c|}{ Masterbatch } & \multicolumn{2}{|c|}{$210 \mathrm{~g}$} \\
\hline \multirow{7}{*}{$\begin{array}{c}\text { Step II } \\
\text { (Two-roll mixing mill) }\end{array}$} & & Mix I [g] & Mix II [g] \\
\hline & Masterbatch* & 105 & 105 \\
\hline & Zinc oxide & 5 & 0 \\
\hline & Stearic acid & 2 & 0 \\
\hline & Zinc dimethyl dithiocarbamate & 7 & 0 \\
\hline & Sulfur & 0.5 & 0 \\
\hline & Dicumyl peroxide & 0 & 2 \\
\hline
\end{tabular}

*All the weight of the curatives are taken in phr 


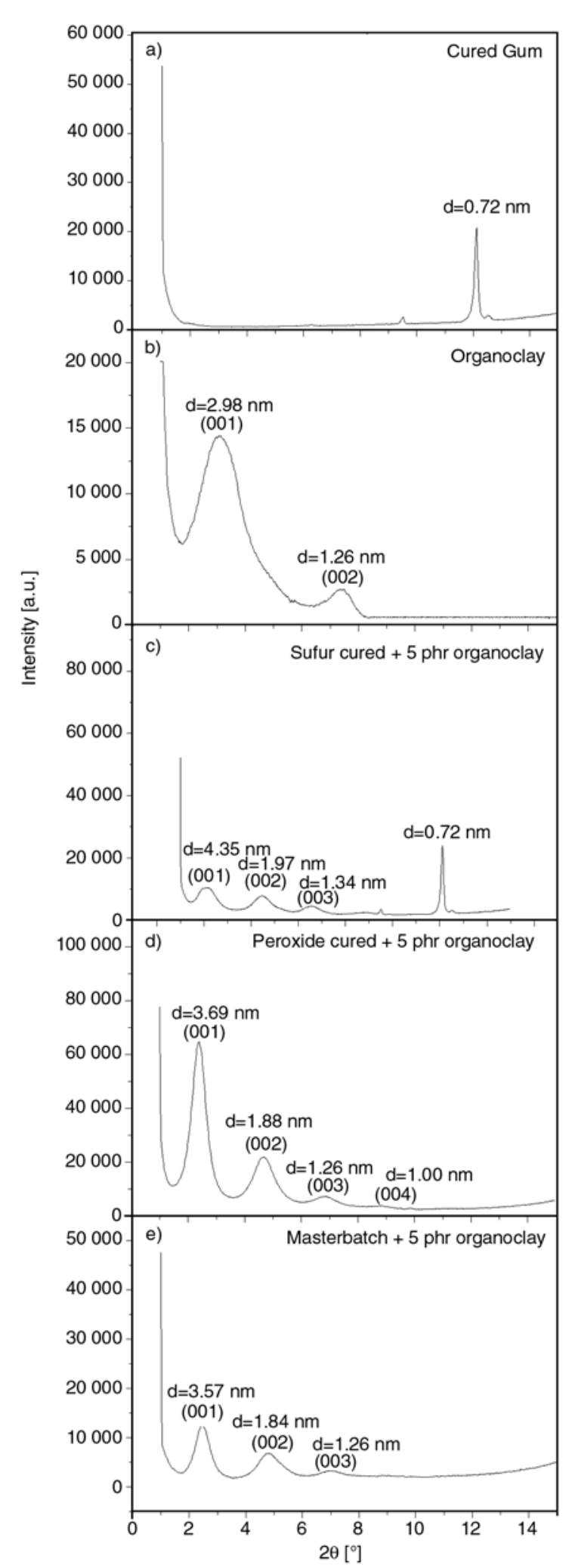

Figure 1. WAXD patterns of (a) cured NBR gum,

(b) organoclay, (c) sulfur cured NBR filled with 5 phr organoclay, (d) peroxide cured NBR filled with 5 phr organoclay and (e) NBR masterbatch filled with 5 phr organoclay

pare the vulcanizates. The rubber samples are prepared in the internal mixer and then by two roll mill

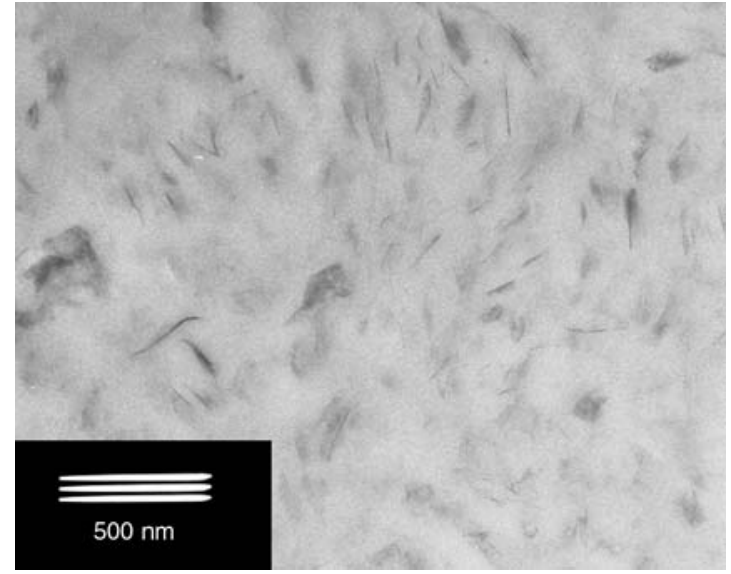

Figure 2. TEM image of sulfur cured NBR matrix filled with 5 phr organoclay

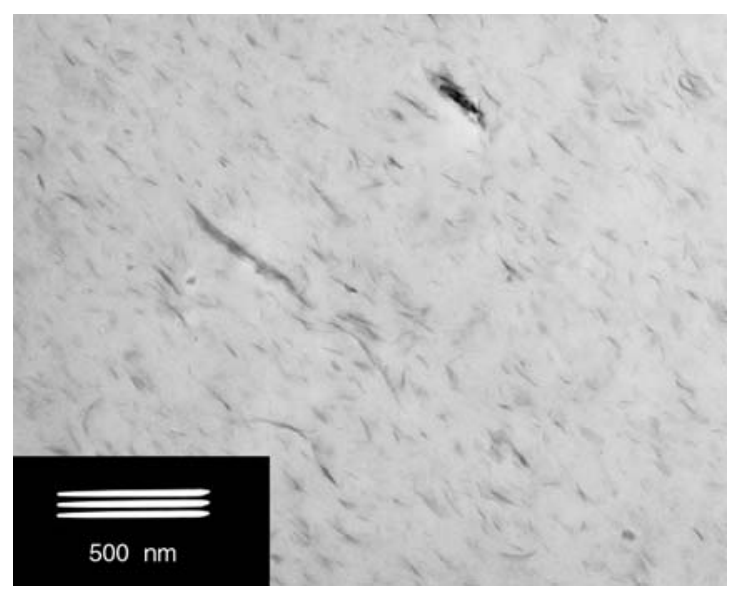

Figure 3. TEM image of peroxide cured NBR matrix filled with 5 phr organoclay

mixing and, finally, hot pressing in a mould. So, it is likely expected that silicate particles are oriented during those processing steps. Since the XRD peak intensity of masterbatch is lower than that of peroxide cured NBR vulcanizate, it can be assumed that most of orientation is likely taking place during mixing by two roll mill. This anisotropic behavior is quite common for layered silicate rubber nanocomposites cured by a peroxide system [2]. So, it can be said at least that in opposite to peroxide curing, sulfur cured vulcanizates show a non-oriented isotropy of the layered silicates. It is assumed that during sulfur curing the conformational rearrangement of the macromolecular chains takes place for providing the sulfur crosslinking sites close together, and in this way the silicate particles are forced to move along with rubber chain in different directions. In the other case of peroxide cured system the rubber chains, more or less, do not sustain further rearrangement in conformations because there a lot of crosslinking sites are available to each other for 


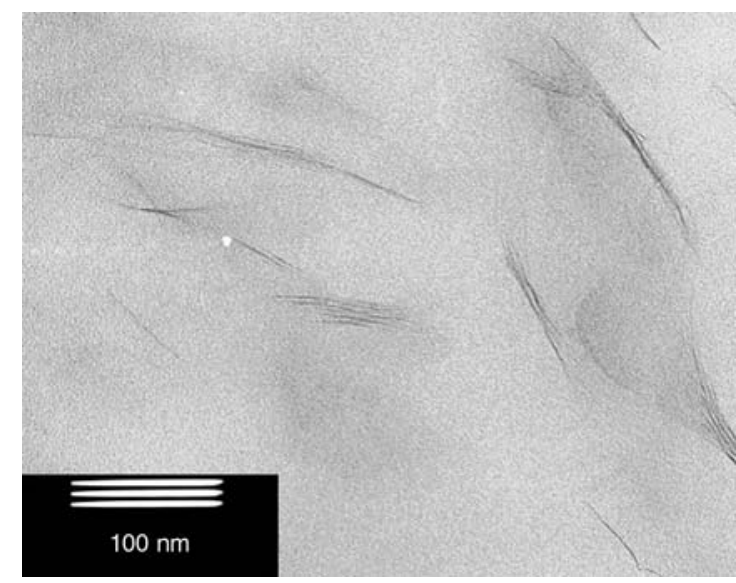

Figure 4. TEM image of sulfur cured NBR filled with 5 phr organoclay

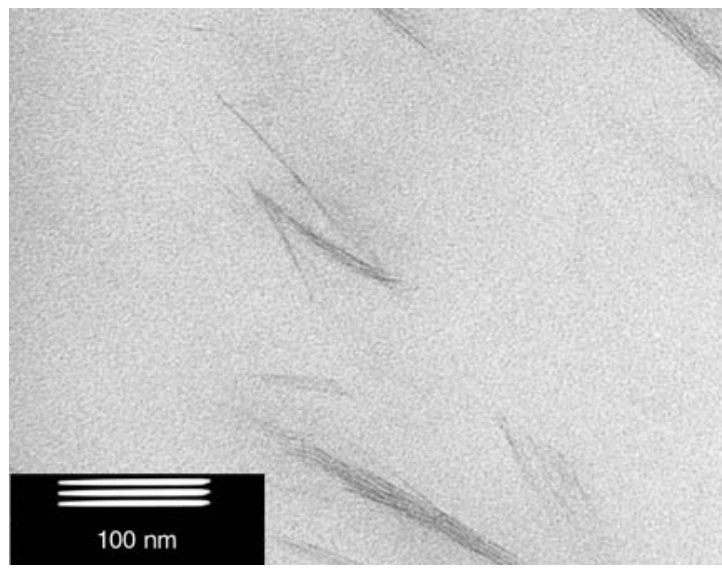

Figure 5. TEM image of peroxide cured NBR matrix filled with 5 phr organoclay

covalent bond formation $(\mathrm{C}-\mathrm{C})$. By a more precise inspection of the TEM pictures, one finds intercalated and exfoliated structures simultaneously. Figure 4 and Figure 5 show magnifications selected from sulfur and peroxide cured vulcanizates, respectively. Here, most of the visible silicate layer thickness is around few nanometers and length is about multiple of hundred nanometers. Single exfoliated layers can also be found from both of them. Therefore, it could be assumed that most of the silicate layers are monolayers, but sometimes couples of layers are also attached together in the intercalated form. Despite all these facts discussed above, intercalation and exfoliation are the common process during the vulcanization reaction irrespective of the curing chemistry in the NBR matrix.

\subsection{Effect of stearic acid}

Zinc oxide, stearic acid, organic accelerators and sulfur are the very common ingredients in curing packages of a diene rubber like polybutadiene rub- ber (BR), styrene butadiene rubber (SBR) natural rubber (NR), etc. The ingredients vulcanize the rubber matrix by sulfur crosslinking under estimated optimum temperature and pressure conditions. Stearic acid in this process plays an important role in the vulcanization mechanism. It dissolves zinc oxide and forms a kind of zinc organic complex with the help of sulfur accelerators. Ultimately, this intermediate reactive sulfur metal complex promotes sulfur crosslinking to the unsaturated rubbers under the vulcanization condition. In our present case we have used different amounts of stearic acid to see the effect of this long chain organic acid on the intercalation/exfoliation process. The XRD pattern of those vulcanizates is shown in Figure 6. It is again remembered that the masterbatch containing $5 \mathrm{phr}$ organoclay leads to a XRD pattern with a basal spacing of the $d_{001}$ plane at $3.57 \mathrm{~nm}$. There are also other higher order reflections corresponding to $d_{002}$ and $d_{003}$ plane. So, after high temperature internal mixing the organoclay obviously remains in a well ordered intercalated form. However, after curing with the addition of vulcanization ingredients with $1 \mathrm{phr}$ stearic acid the basal spacing of $d_{001}$ plane shifts to lower angles corresponding a $d_{001}$ plane gap of $4.12 \mathrm{~nm}$. Obviously, during the sulfur vulcanization further intercalation is taking place. It is also observed that at higher angles at around $9.5^{\circ}$ and $12^{\circ}$ two sharp peaks arise. It should be noted here that these two peaks are also present even from the gum and they are absent in peroxide cured vulcanizates. So it may be speculated that these peaks may be due to the presence of $\mathrm{Zn}$-sulfur-organic accelerators complex, with crystalline character, which are produced in-situ during the vulcanization reaction.

After addition of $2 \mathrm{phr}$ stearic acid the basal peak corresponding to $d_{001}$ was further shifted toward more lower angles, and the value of corresponding $d_{001}$ spacing is $4.35 \mathrm{~nm}$. A very interesting XRD scattering was found when using $4 \mathrm{phr}$ stearic acid in the vulcanization process. The curve obtained from the corresponding vulcanizate shows almost exfoliated type structures of the layered silicates. However, there are also some very broad peaks with very low intensity which signifies the existence of some intercalated layers with uneven space gap of the silicate layers.

For a better understanding of the enhancement of physical properties with variations of stearic acid 

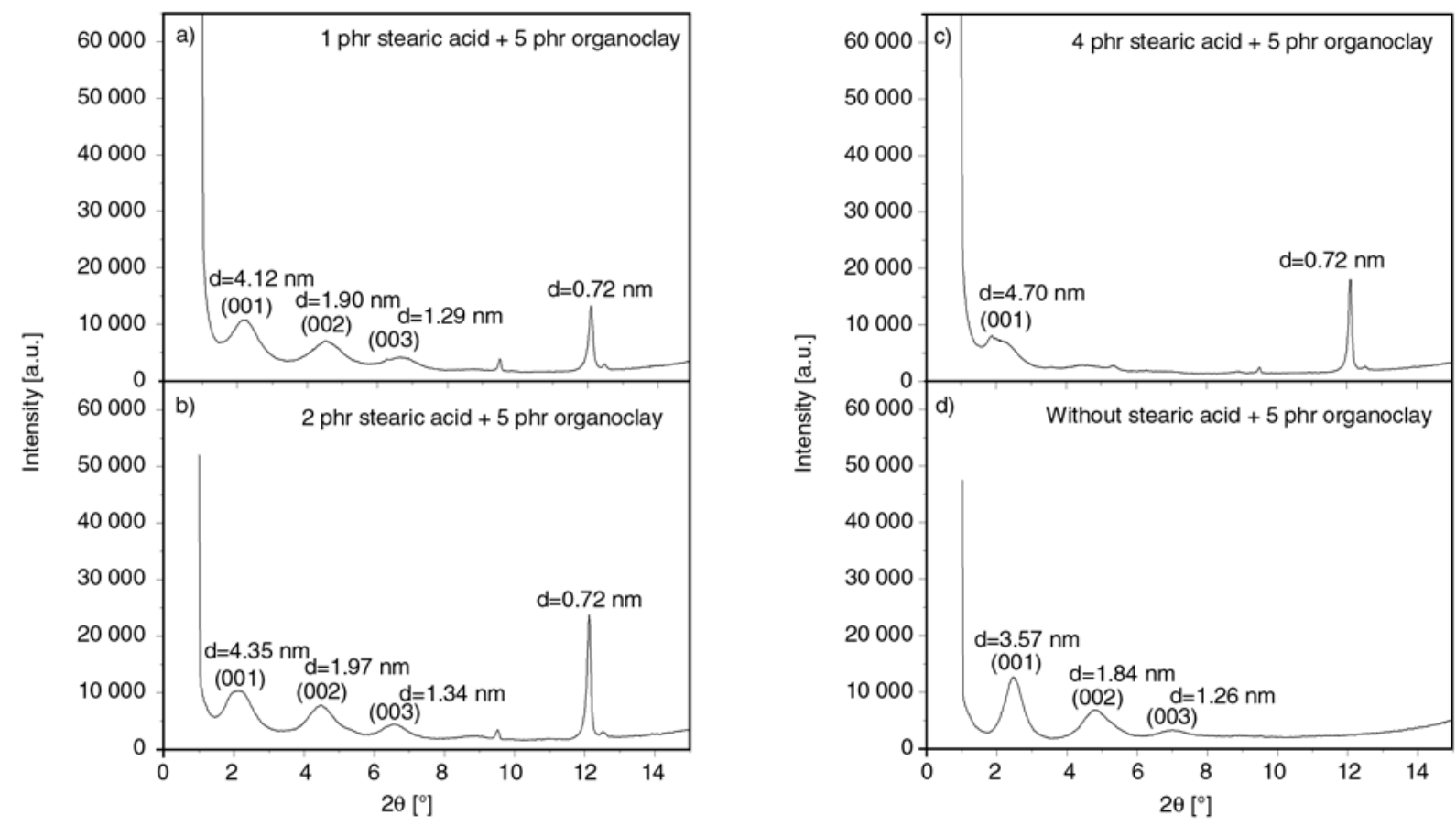

Figure 6. WAXD patterns of NBR filled ( 5 phr organoclay) vulcanizates formulated with(a) 1 phr stearic acid, (b) 2 phr stearic acid, (c) 4 phr stearic acid and (e) without stearic acid

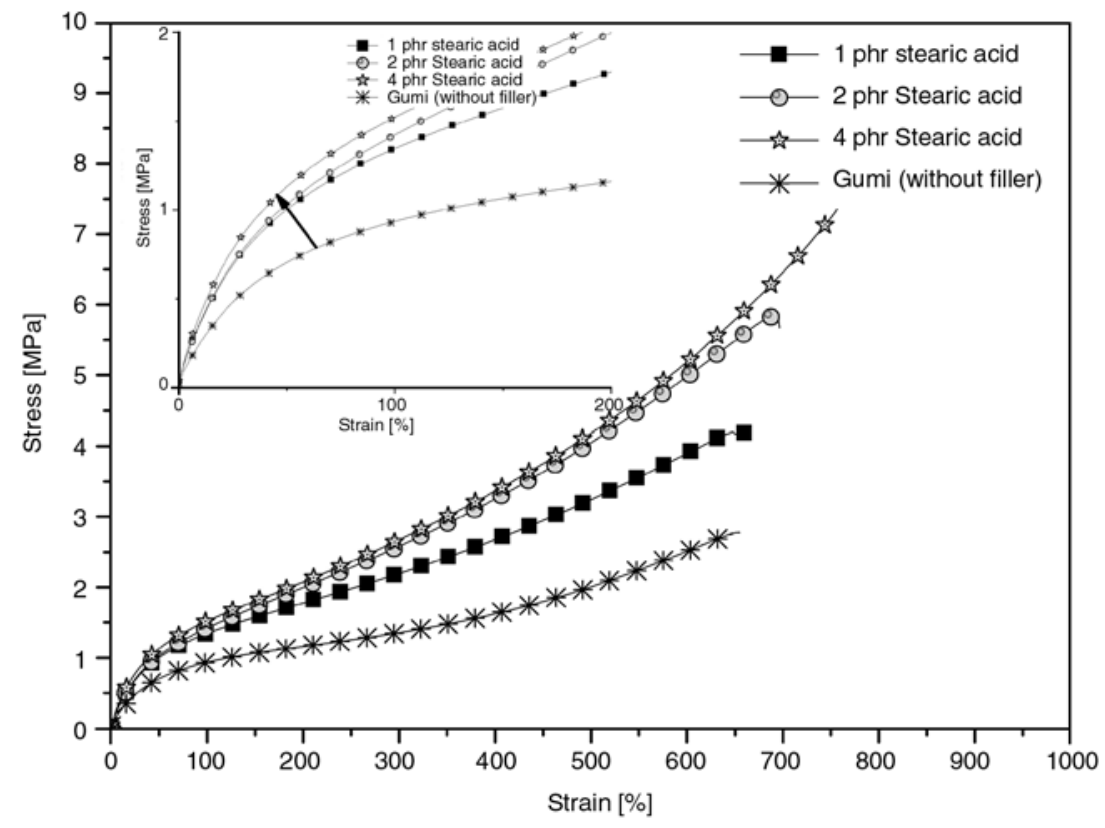

Figure 7. Stress-Strain diagrams of organoclay filled NBR formulated with different amount of stearic acid

the stress-strain plots from tensile experiments are displayed in Figure 7. The curve obtained from gum rubber without any filler and with $1 \mathrm{phr}$ stearic acid shows a very low tensile strength, and an elongation at break of around $650 \%$. With increasing amount of stearic acid up to $2 \mathrm{phr}$ in the filled NBRs the curves become stronger and steeper. Elongation at break values do not change significantly in comparison to the gum rubber. However, at $4 \mathrm{phr}$ stearic acid content the tensile strength and elongation at break increase considerably. We presume that stearic acid promotes the silicate layers to disperse uniformly with a sufficient degree of exfoliation and intercalation, and therefore the rubber matrix becomes strongly reinforced.

\section{Conclusions}

Both sulfur and peroxide vulcanizations of NBR filled with organoclay lead to intercalated-exfoli- 
ated structures of the layered silicate. Peroxide vulcanization brings the silicate layers into well ordered arrangements in a particular direction. This kind of alignment of the layered silicates in the rubber matrix could be of advantage for a more effective hindering of gas permeability. However, peroxide curing also promotes exfoliated structures as evinced from TEM and reflected by the XRD experiments. We demonstrated that the use of excess stearic acid could be a way for getting better exfoliation of the layered silicate in the rubber matrix when sulfur vulcanization will be selected for curing the rubber matrix. Keeping the layered silicate arrangement in mind, it can be envisaged that the choice of peroxide curing packages might have a beneficial effect on the reduction of gas permeability of a rubber nanocomposite. Excess use of stearic acid in the vulcanization ingredients does not affect the curing properties of NBR, but in turn increases the tensile and modulus of the vulcanizates. The detailed physical properties will be shown in our forthcoming publications.

We finally note that after completing the manuscript a similar effect of stearic acid in EPDMorganoclay nanocomposites has been reported in reference [15]. The tensile strength of the corresponding nanocomposites could be improved with increasing amount of stearic acid, whereas the stresses at low strain were almost the same.

\section{Acknowledgements}

This work has been supported by the German Federal Ministry of Education and Research (BMB Grant 03X0002E F). We are thankful to Dr. Thomas Engelhardt of SüdChemie AG, Moosburg (G) for providing the XRD studies.

\section{References}

[1] Carrado K. A.: Synthetic organo-and polymer-clays: preparation, characterization and materials applications. Applied Clay Science, 17, 1-23 (2000).

[2] Herrmann W., Uhl C., Heinrich G., Jehnichen D.: Analysis of HNBR-montmorillonite nanocomposites morphology, orientation and macroscopic properties. Polymer Bulletin, 57, 395-405 (2006).

[3] Lebaron P. C., Pinnavaia T. J.: Clay nanolayer reinforcement of a silicone elastomer. Chemistry of Materials, 13, 3760-3765 (2001).
[4] Usuki A., Tukigase A., Kato M.: Preparation and properties of EPDM-clay hybrids. Polymer, 43, 2185-2189 (2002).

[5] Varghese S., Karger-Kocsis J.: Melt-compounded natural rubber nanocomposites with pristine and organophilic layered silicates of natural and synthetic origin. Journal of Applied Polymer Science, 91, 813-819 (2004).

[6] Liu B., Ding Q., He Q., Cai J., Hu B., Shen J.: Novel preparation and properties of EPDM/montmorillonite nanocomposites. Journal of Applied Polymer Science, 99, 2578-2585 (2006).

[7] Wu Y-P., Jia Q-X., Yu D-S., Zhang L-Q.: Structure and properties of nitrile rubber (NBR)-clay nanocomposites by co-coagulating NBR latex and clay aqueous suspension. Journal of Applied Polymer Science, 89, 3855-3858 (2003).

[8] Hwang W-G., Wei K-W, Wu C-M.: Preparation and mechanical properties of nitrile butadiene rubber/silicate nanocomposites. Polymer, 45, 5729-5734 (2004).

[9] Wu Y-P., Zhang L-Q., Wang Y-Q., Liang Y., Yu DS.: Structure of carboxylated acrylonitrile-butadiene rubber (CNBR)-clay nanocomposites by co-coagulating rubber latex and clay aqueous suspension. Journal of Applied Polymer Science, 82, 2842-2848 (2001).

[10] Liu L., Jia D., Luo Y., Guo B.: Preparation, structure and properties of nitrile-butadiene rubber-organoclay nanocomposites by reactive mixing intercalation method. Journal of Applied Polymer Science, 100, 1905-1913 (2006).

[11] Gatos K. G., Thomann R., Karger-Kocsis J.: Characteristics of ethylene propylene diene monomer rubber/organoclay nanocomposites resulting from different processing conditions and formulations. Polymer International, 53, 1191-1197 (2004).

[12] Gatos K. G., Sawanis N. S., Apostolov A. A., Thomann R., Karger-Kocsis J.: Nanocomposite formation in hydrogenated nitrile rubber (HNBR)/ organo-montmorillonite as a function of intercalant type. Macromolecular Materials and Engineering, 289, 1079-1086 (2004).

[13] Gatos K. G., Százdi L., Pukánszky B., Karger-Kocsis J.: Controlling the deintercalation in hydrogenated nitrile rubber (HNBR)/organo-montmorillonite nanocomposites by curing with peroxide. Macromolecular Rapid Communications, 26, 915-919 (2005).

[14] Vaia R. A., Liu W.: X-ray powder diffraction of polymer-layered silicate nanocomposites: Model and practice. Journal of Polymer Science, Part B: Polymer Physics, 40, 1590-1600 (2002).

[15] Ma Y., Li Q-F., Zhang L-Q., Wu Y-P.: Role of stearic acid in preparing EPDM/clay nanocomposites by melt compounding. Polymer Journal, 39, 48-54 (2007). 